\title{
Fixed and coupled fixed points of a new type set-valued contractive mappings in complete metric spaces
}

\section{A Amini-Harandi*}

\section{"Correspondence:}

aminih_a@yahoo.com

Department of Pure Mathematics,

University of Shahrekord,

Shahrekord, 88186-34141, Iran

School of Mathematics, Institute for

Research in Fundamental Sciences (IPM), P.O. Box 19395-5746, Tehran, Iran

\begin{abstract}
In this paper, motivated by the recent work of Wardowski (Fixed Point Theory Appl. 2012:94, 2012), we introduce a new concept of set-valued contraction and prove a fixed point theorem which generalizes some well-known results in the literature. As an application, we derive a new coupled fixed point theorem. Some examples are also given to support our main results.
\end{abstract}

MSC: $47 \mathrm{H} 10$

Keywords: fixed point; coupled fixed point; set-valued contractions

\section{Introduction}

In the literature, there are plenty of extensions of the famous Banach contraction principle [1], which states that every self-mapping $T$ defined on a complete metric space $(X, d)$ satisfying

$$
d(T x, T y) \leq k d(x, y) \quad \text { for each } x, y \in X,
$$

where $k \in[0 ; 1)$, has a unique fixed point, and for every $x_{0} \in X$, the sequence $\left\{T^{n} x_{0}\right\}_{n \in \mathbb{N}}$ is convergent to the fixed point. Some of the extensions weaken the right side of the inequality in the condition (1) by replacing $k$ with a mapping; see, e.g., [2-4]. In other results, the underlying space is more general; see, e.g., [5-8]. In 1969, Nadler [9] extended the Banach contraction principle to set-valued mappings. For other extensions of the Banach contraction principle, see [10-21] and the references therein.

Recently, Wardowski [22] introduced a new concept of contraction and proved a fixed point theorem which generalizes the Banach contraction principle in a different way than in the known results from the literature. In this paper, we present an improvement and generalization of the main result of Wardowski [22]. To set up our results, in the next section, we introduce some definitions and facts.

Let $(X, d)$ be a metric space and let $C B(X)$ denote the class of all nonempty bounded closed subsets of $X$. Let $H$ be the Hausdorff metric with respect to $d$, that is,

$$
H(A, B)=\max \left\{\sup _{u \in A} d(u, B), \sup _{v \in B} d(v, A)\right\}
$$

for every $A, B \in C B(X)$, where $d(u, B)=\inf \{d(u, y): y \in B\}$. 
Theorem 1.1 (Nadler [9]) Let $(X, d)$ be a complete metric space and let $T: X \rightarrow C B(X)$ be a set-valued map. Assume that there exists $k \in[0,1)$ such that

$$
H(T x, T y) \leq k d(x, y) \quad \text { for each } x, y \in X .
$$

Then $T$ has a fixed point.

In 1989 Mizoguchi and Takahashi [13] proved the following generalization of Theorem 1.1.

Theorem 1.2 (Mizoguchi and Takahashi [13]) Let $(X, d)$ be a complete metric space and let $T: X \rightarrow C B(X)$ be a set-valued map satisfying

$$
H(T x, T y) \leq \alpha(d(x, y)) d(x, y) \quad \text { for each } x, y \in X,
$$

where $\alpha:[0, \infty) \rightarrow[0,1)$ satisfies $\lim \sup _{t \rightarrow r^{+}} \alpha(t)<1$ for each $r \in[0, \infty)$. Then $T$ has $a$ fixed point.

\section{Main results}

Let $F:(0, \infty) \rightarrow \mathbb{R}$ and $\theta:(0, \infty) \rightarrow(0, \infty)$ be two mappings. Throughout the paper, let $\Delta$ be the set of all pairs $(F, \theta)$ satisfying the following:

$\left(\delta_{1}\right) \theta\left(t_{n}\right) \not \rightarrow 0$ for each strictly decreasing sequence $\left\{t_{n}\right\}$;

$\left(\delta_{2}\right) F$ is strictly increasing;

$\left(\delta_{3}\right)$ For each sequence $\left\{\alpha_{n}\right\}_{n \in \mathbb{N}}$ of positive numbers, $\lim _{n \rightarrow \infty} \alpha_{n}=0$ if and only if $\lim _{n \rightarrow \infty} F\left(\alpha_{n}\right)=-\infty$;

$\left(\delta_{4}\right)$ If $t_{n} \downarrow 0$ and $\theta\left(t_{n}\right) \leq F\left(t_{n}\right)-F\left(t_{n+1}\right)$ for each $n \in \mathbb{N}$, then $\sum_{n=1}^{\infty} t_{n}<\infty$.

Example 2.1 Let $\theta_{1}(t)=\tau$ for each $t \in(0, \infty)$, where $\tau>0$ is a constant, and let $F_{1}$ : $(0, \infty) \rightarrow \mathbb{R}$ be a mapping satisfying $\lim _{x \rightarrow 0^{+}} x^{k} F(x)=0$ for some $k \in(0,1)$ where $F$ : $(0, \infty) \rightarrow \mathbb{R}$ is strictly increasing. Then the proof of the main result in [22] shows that $\left(F_{1}, \theta_{1}\right) \in \Delta$. We give the details for completeness. Using $\left(\delta_{4}\right)$, the following holds for every $n \in \mathbb{N}:$

$$
F\left(t_{n}\right) \leq F\left(t_{n-1}\right)-\tau \leq F\left(t_{n-2}\right)-2 \tau \leq \cdots \leq F\left(t_{0}\right)-n \tau .
$$

By (3), the following holds for every $n \in \mathbb{N}$ :

$$
t_{n}^{k} F\left(t_{n}\right)-t_{n}^{k} F\left(t_{0}\right) \leq t_{n}^{k}\left(F\left(t_{0}\right)-n \tau\right)-t_{n}^{k} F\left(t_{0}\right)=-t_{n}^{k} n \tau \leq 0 .
$$

Since $\lim _{n \rightarrow \infty} t_{n}^{k} F\left(t_{n}\right)=0$, letting $n \rightarrow \infty$ in (4), we obtain $\lim _{n \rightarrow \infty} n t_{n}^{k}=0$. Then there exists $n_{1} \in \mathbb{N}$ such that $n t_{n}^{k} \leq 1$ for $n \geq n_{1}$. Consequently, we have $t_{n} \leq \frac{1}{n^{\frac{1}{k}}}$ for all $n \geq n_{1}$. Thus, $\sum_{n=1}^{\infty} t_{n}<\infty$ (note that $\left.\sum_{n=1}^{\infty} \frac{1}{n^{\frac{1}{k}}}<\infty\right)$.

Example 2.2 Let $F_{2}(t)=\ln t$ and let $\theta_{2}(t)=-\ln (\alpha(t))$ for each $t \in(0, \infty)$, where $\alpha$ : $(0, \infty) \rightarrow[0,1)$ satisfying

$$
\limsup _{t \rightarrow r^{+}} \alpha(t)<1 \quad \text { for each } r \in[0, \infty) \text {. }
$$


Now, we show that $\left(F_{2}, \theta_{2}\right) \in \Delta$. It is easy to see that $F_{2}$ and $\theta_{2}$ satisfy $\left(\delta_{1}\right)-\left(\delta_{3}\right)$. To show $\left(\delta_{4}\right)$, assume that $t_{n} \downarrow 0$ and

$$
-\ln \left(\alpha\left(t_{n}\right)\right) \leq \ln t_{n}-\ln t_{n+1} \quad \forall n \in \mathbb{N}
$$

Then $t_{n+1} \leq \alpha\left(t_{n}\right) t_{n}$ for each $n \in \mathbb{N}$. Since $\lim \sup _{t \rightarrow 0^{+}} \alpha(t)<1$, then there exist $n_{0} \in \mathbb{N}$ and $0<r<1$ such that $\alpha\left(t_{n}\right)<r$ for $n \geq n_{0}$. Thus, $t_{n+1} \leq r t_{n}$ for each $n \geq n_{0}$, and so $\sum_{n=1}^{\infty} t_{n}<\infty$.

Example 2.3 Let $F_{3}(t)=\ln t+t$ and let $\theta_{3}(t)=\tau$ for each $t \in(0, \infty)$, where $\tau>0$ is a constant. Now, we show that $\left(F_{3}, \theta_{3}\right) \in \Delta$. We only show $\left(\delta_{4}\right)$. Suppose that $t_{n} \rightarrow 0$ and

$$
\tau \leq\left(\ln t_{n}+t_{n}\right)-\left(\ln t_{n+1}+t_{n+1}\right) \quad \forall n \in \mathbb{N}
$$

Then

$$
s_{n+1} \leq e^{-\tau} s_{n} \quad \forall n \in \mathbb{N},
$$

where $s_{n}=t_{n} e^{t_{n}}$. Since $e^{-\tau}<1$, then from the above we get $\sum_{n=1}^{\infty} s_{n}<\infty$, and so $\sum_{n=1}^{\infty} t_{n}<\infty$ (note that $t_{n} \leq s_{n}$ for each $n \in \mathbb{N}$ ).

Now, we state the main result of the paper.

Theorem 2.4 Let $(X, d)$ be a complete metric spaces, let $T: X \rightarrow C B(X)$ be a set-valued mapping and let $\left(F, \frac{\theta}{2}\right) \in \Delta$. Assume that either $T$ is compact valued or $F$ is continuous from the right. Furthermore, assume that

$$
\theta(d(x, y))+F(H(T x, T y)) \leq F(d(x, y)) \quad \forall x, y \in X \text { with } T x \neq T y
$$

Then T has a fixed point.

Proof Let $x_{0} \in X$ and $x_{1} \in T x_{0}$. If $T x_{0}=T x_{1}$, then $x_{1} \in T x_{0}=T x_{1}$ and $x_{1}$ is a fixed point of $T$. So, we may assume that $T x_{0} \neq T x_{1}$. Since either $T$ is compact valued or $F$ is continuous from the right, $x_{1} \in T x_{0}$ and $F\left(d\left(x_{1}, T x_{1}\right)\right)<F\left(H\left(T x_{0}, T x_{1}\right)\right)+\frac{\theta\left(d\left(x_{0}, x_{1}\right)\right)}{2}$ then there exists $x_{2} \in$ $T x_{1}$ such that (note that $F$ is increasing)

$$
F\left(d\left(x_{1}, x_{2}\right)\right) \leq F\left(H\left(T x_{0}, T x_{1}\right)\right)+\frac{\theta\left(d\left(x_{0}, x_{1}\right)\right)}{2} .
$$

From (5) and (6), we have

$$
\begin{aligned}
& \theta\left(d\left(x_{0}, x_{1}\right)\right)+F\left(d\left(x_{1}, x_{2}\right)\right) \\
& \quad \leq \theta\left(d\left(x_{0}, x_{1}\right)\right)+F\left(H\left(T x_{0}, T x_{1}\right)\right)+\frac{\theta\left(d\left(x_{0}, x_{1}\right)\right)}{2} \leq F\left(d\left(x_{0}, x_{1}\right)\right)+\frac{\theta\left(d\left(x_{0}, x_{1}\right)\right)}{2}
\end{aligned}
$$

and so

$$
\frac{\theta\left(d\left(x_{0}, x_{1}\right)\right)}{2}+F\left(d\left(x_{1}, x_{2}\right)\right) \leq F\left(d\left(x_{0}, x_{1}\right)\right) .
$$


We may also assume that $T x_{1} \neq T x_{2}$ (otherwise, $x_{2} \in T x_{2}=T x_{1}$ ). Proceeding this manner, we can define a sequence $\left\{x_{n}\right\}$ in $X$ satisfying

$$
x_{n+1} \in T x_{n}, \quad \frac{\theta\left(t_{n}\right)}{2} \leq F\left(t_{n}\right)-F\left(t_{n+1}\right), \quad \text { for each } n \in \mathbb{N},
$$

where $t_{n}=d\left(x_{n}, x_{n+1}\right)$. Since $\theta\left(t_{n}\right)>0$ then from (8), we have $F\left(t_{n}\right)>F\left(t_{n+1}\right)$ for each $n \in \mathbb{N}$. Since $F$ is strictly increasing, then we deduce that $\left\{t_{n}\right\}$ is a nonnegative strictly decreasing sequence and so is convergent to some $r \geq 0, \lim _{n \rightarrow \infty} t_{n}=r$. Now we show that $r=0$. On the contrary, assume that $r>0$. From (8), we get

$$
\frac{1}{2} \sum_{i=1}^{n} \theta\left(t_{i}\right) \leq F\left(t_{1}\right)-F\left(t_{n+1}\right) \quad \text { for each } n \in \mathbb{N} .
$$

Since $\left\{t_{n}\right\}$ is strictly decreasing, then from $\left(\delta_{1}\right)$ we get $\theta\left(t_{n}\right) \nrightarrow \rightarrow 0$. Thus, $\sum_{i=1}^{\infty} \theta\left(t_{i}\right)=\infty$, and then from (9), we have $\lim _{n \rightarrow \infty} F\left(t_{n}\right)=-\infty$. Then by $\left(\delta_{3}\right), t_{n} \rightarrow 0$, a contradiction. Hence,

$$
\lim _{n \rightarrow \infty} t_{n}=0 .
$$

From (8), (10) and $\left(\delta_{4}\right)$, we have

$$
\sum_{i=1}^{\infty} t_{i}=\sum_{i=1}^{\infty} d\left(x_{i}, x_{i+1}\right)<\infty
$$

Then, by the triangle inequality, $\left\{x_{n}\right\}$ is a Cauchy sequence. From the completeness of $X$, there exists $x \in X$ such that $\lim _{n \rightarrow \infty} x_{n}=x$. Now, we prove that $x$ is a fixed point of $T$. To prove the claim, we may assume that $T x_{n} \neq T x$ for sufficiently large $n \in \mathbb{N}$. On the contrary, assume that $T x_{n_{i}}=T x$ for each $i \in \mathbb{N}$. Since $T x$ is closed, $x_{n_{i}+1} \in T x_{n_{i}}=T x$ and $x_{n_{i}+1} \rightarrow x$, then $x \in T x$, and we are finished.

From (5), we have (note that $x_{n+1} \in T x_{n}$ and $T x_{n} \neq T x$ for $n \geq N$ )

$$
\begin{aligned}
F\left(d\left(x_{n+1}, T x\right)\right) & \leq \theta\left(d\left(x_{n}, x\right)\right)+F\left(d\left(x_{n+1}, T x\right)\right) \\
& \leq \theta\left(d\left(x_{n}, x\right)\right)+F\left(H\left(T x_{n}, T x\right)\right) \leq F\left(d\left(x_{n}, x\right)\right) .
\end{aligned}
$$

Since $d\left(x_{n}, x\right) \rightarrow 0$, then (11) together with $\left(\delta_{3}\right)$ imply that

$$
d(x, T x)=\lim _{n \rightarrow \infty} d\left(x_{n+1}, T x\right)=0
$$

and so $d(x, T x)=0$. Hence, $x \in T x$ (note that $T x$ is closed).

Remark 2.5 By Example 2.1, Theorem 2.4 is an extension and improvement of Theorem 2.1 of Wardowski [22]. From Example 2.2, we infer that Theorem 2.4 is a generalization of the above mentioned Theorem 1.2 of Mizoguchi and Takahashi.

Now, we illustrate our main result by the following example. 
Example 2.6 Consider the complete metric space $(X=\{0,1,2,3, \ldots\}, d)$, where $d$ is defined as

$$
d(x, y)= \begin{cases}0, & x=y \\ x+y, & x \neq y\end{cases}
$$

Let $T: X \rightarrow C B(X)$ be defined as

$$
T x= \begin{cases}\{0,1,2,3, \ldots\}, & x=0, \\ \{x-1, x, x+1, \ldots\}, & x>0 .\end{cases}
$$

Let $f: X \rightarrow X$ be given by

$$
f x= \begin{cases}0, & x=0 \\ x-1, & x>0\end{cases}
$$

Now, we show that $T$ satisfies (5), where $\theta(t)=1$ for each $t \in(0, \infty)$ and $F(x)=\ln x+x$ for each $x \in(0, \infty)$. To show the claim, notice first that $H\left(T x_{1}, T x_{2}\right)=d\left(f x_{1}, f x_{2}\right)$ for each $x_{1}, x_{2} \in X$. Now let $x_{1}, x_{2} \in X$ with $f x_{1} \neq f x_{2}$. Since $d\left(f x_{1}, f x_{2}\right)-d\left(x_{1}, x_{2}\right) \leq-1$, then we have

$$
\frac{d\left(f x_{1}, f x_{2}\right)}{d\left(x_{1}, x_{2}\right)} e^{d\left(f x_{1}, f x_{2}\right)-d\left(x_{1}, x_{2}\right)} \leq e^{-1}, \quad \text { for each } x_{1}, x_{2} \in X \text { with } f x_{1} \neq f x_{2} .
$$

Thus, from the above, we have

$$
\begin{aligned}
1 & \leq\left[\ln d\left(x_{1}, x_{2}\right)+d\left(x_{1}, x_{2}\right)\right]-\left[\ln d\left(f x_{1}, f x_{2}\right)+d\left(f x_{1}, f x_{2}\right)\right] \\
& =F\left(d\left(x_{1}, x_{2}\right)\right)-F\left(d\left(f x_{1}, f x_{2}\right)\right) .
\end{aligned}
$$

Therefore, (note that $\left.H\left(T x_{1}, T x_{2}\right)=d\left(f x_{1}, f x_{2}\right)\right)$

$$
1 \leq F\left(d\left(x_{1}, x_{2}\right)\right)-F\left(H\left(T x_{1}, T x_{2}\right)\right) .
$$

Then, by Theorem 2.4, $T$ has a fixed point.

Now, we show that $T$ does not satisfy the condition of Nadler's theorem. On the contrary, assume that there exists a function $k \in[0,1)$ such that

$$
H\left(T x_{1}, T x_{2}\right) \leq k d\left(x_{1}, x_{2}\right)
$$

for all $x_{1}, x_{2} \in X$. Then

$$
d\left(f x_{1}, f x_{2}\right) \leq k d\left(x_{1}, x_{2}\right)
$$

Then, for each $x_{1}>1$ and $x_{2}=x_{1}+1$, we have

$$
2 x_{1}-1 \leq k\left(2 x_{1}+1\right), \quad \text { for each } x_{1}>1 \text {. }
$$


Hence,

$$
1=\lim _{x_{1} \rightarrow \infty} \frac{2 x_{1}-1}{2 x_{1}+1} \leq k
$$

a contradiction.

Example 2.7 For each $t \in(0, \infty)$, let $F_{4}(t)=-\frac{1}{t}$ and let

$$
\theta_{4}(t)= \begin{cases}-\frac{\ln t}{t}, & 0<t<1 \\ 1, & 1 \leq t\end{cases}
$$

Then it is easy to see that $\left(F_{4}, \theta_{4}\right) \in \Delta$, but $F_{4}$ does not satisfy the condition $\left(F_{3}\right)$ of the definition of $F$-contraction in [22].

Now, by using the technique in [23], we present a new coupled fixed point result. For more details on coupled fixed point theory, see [23-25] and the references therein.

Corollary 2.8 Let $(M, \rho)$ be a complete metric space and let $\left(F, \frac{\theta}{2}\right) \in \Delta$. Let $f: M \times M \rightarrow M$ be a mapping satisfying

$$
\begin{aligned}
& \theta(\rho(x, u)+\rho(y, v))+F(\rho(f(x, y), f(u, v))+\rho(f(y, x), f(v, u))) \\
& \quad \leq F(\rho(x, u)+\rho(y, v))
\end{aligned}
$$

for each $x, y, u, v \in M$. Then $f$ has a coupled fixed point $\left(x_{0}, y_{0}\right)$, that is, $f\left(x_{0}, y_{0}\right)=x_{0}$ and $f\left(y_{0}, x_{0}\right)=y_{0}$.

Proof Let $X=M \times M$ and let $d$ be the metric on $M$ which is defined by

$$
d((x, y),(u, v))=\rho(x, u)+\rho(y, v) .
$$

Then it is straightforward to show that $(X, d)$ is a complete metric space. Let $T: X \rightarrow X$ be defined by $T(x, y)=(f(x, y), f(y, x))$. From (12), we get

$$
\theta(d((x, y),(u, v)))+F(d(T(x, y), T(u, v))) \leq F(d((x, y),(u, v)))
$$

for each $(x, y),(u, v) \in X$. Then from Theorem 2.4 we deduce that $T$ has a fixed point $u_{0}=$ $\left(x_{0}, y_{0}\right)$. Then $\left(x_{0}, y_{0}\right)$ is a coupled fixed point of $f$.

\section{Competing interests}

The author declares that they have no competing interests.

\section{Acknowledgements}

The author is grateful to the referees for their helpful comments leading to improvement of the presentation of the work. This work was supported by the University of Shahrekord and by the Center of Excellence for Mathematics, University of Shahrekord, Iran. This research was also in part supported by a grant from IPM (No. 91470412). This research is partially carried out in the IPM-Isfahan Branch. 


\section{References}

1. Banach, S: Sur les opérations dans les ensembles abstraits et leur applications aux équations intégrales. Fundam. Math. 3, 133-181 (1922)

2. Boyd, DW, Wong, JSW: On nonlinear contractions. Proc. Am. Math. Soc. 20, 458-464 (1969)

3. Rakotch, E: A note on contractive mappings. Proc. Am. Math. Soc. 13, 459-465 (1962)

4. Geraghty, G: On contractive mappings. Proc. Am. Math. Soc. 40, 604-608 (1973)

5. Arandjelovic, I, Kadelburg, Z, Radenovic, S: Boyd-Wong-type common fixed point results in cone metric spaces. Appl. Math. Comput. 217, 7167-7171 (2011)

6. Huang, LG, Zhang, X: Cone metric spaces and fixed point theorems of contractive maps. J. Math. Anal. Appl. 332 , 1467-1475 (2007)

7. Kadelburg, Z, Radenovic, S, Rakocevic, V: Remarks on 'Quasi-contraction on a cone metric space'. Appl. Math. Lett. 22, 1674-1679 (2009)

8. Tarafdar, E: An approach to fixed-point theorems on uniform spaces. Trans. Am. Math. Soc. 191, $209-225$ (1974)

9. Nadler, SB Jr.: Multi-valued contraction mappings. Pac. J. Math. 30, 475-488 (1969)

10. Ćirić, L: Multi-valued nonlinear contraction mappings. Nonlinear Anal. 71, 2716-2723 (2009)

11. Feng, Y, Liu, S: Fixed point theorems for multi-valued contractive mappings and multi-valued Caristi type mappings. J. Math. Anal. Appl. 317, 103-112 (2006)

12. Klim, D, Wardowski, D: Fixed point theorems for set-valued contractions in complete metric spaces. J. Math. Anal. Appl. 334, 132-139 (2007)

13. Mizoguchi, N, Takahashi, W: Fixed point theorems for multivalued mappings on complete metric spaces. J. Math Anal. Appl. 141, 177-188 (1989)

14. Amini-Harandi, A, O'Regan, D: Fixed point theorems for set-valued contraction type maps in metric spaces. Fixed Point Theory Appl. 2010, Article ID 390183 (2010). doi:10.1155/2010/390183

15. Wardowski, D: On set-valued contractions of Nadler type in cone metric spaces. Appl. Math. Lett. 24, $275-278$ (2011)

16. Kirk, WA: Fixed points of asymptotic contractions. J. Math. Anal. Appl. 277, 645-650 (2003)

17. Jachymski, J, Józwik, I: On Kirk's asymptotic contractions. J. Math. Anal. Appl. 300, 147-159 (2004)

18. Suzuki, T: Fixed-point theorem for asymptotic contractions of Meir-Keeler type in complete metric spaces. Nonlinear Anal. 64, 971-978 (2006)

19. Choudhury, BS, Konar, P, Rhoades, BE, Metiya, N: Fixed point theorems for generalized weakly contractive mappings. Nonlinear Anal. 74, 2116-2126 (2011)

20. Hussain, N, Amini-Harandi, A, Cho, YJ: Approximate endpoints for set-valued contractions in metric spaces. Fixed Point Theory Appl. 2010, Article ID 614867 (2010). doi:10.1155/2010/614867

21. Hussain, N, Abbas, M: Common fixed point results for two new classes of hybrid pairs in symmetric spaces. Appl. Math. Comput. 218, 542-547 (2011)

22. Wardowski, D: Fixed points of a new type of contractive mappings in complete metric spaces. Fixed Point Theory Appl. 2012, 94 (2012). doi:10.1186/1687-1812-2012-94

23. Amini-Harandi, A: Coupled and tripled fixed point theory in partially ordered metric spaces with application to initial value problem. Math. Comput. Model. (2012). doi:10.1016/j.mcm.2011.12.006

24. Gnana Bhaskar, T, Lakshmikantham, V: Fixed point theorems in partially ordered metric spaces and applications. Nonlinear Anal. 65, 1379-1393 (2006)

25. Lakshmikantham, V, Ćirić, L: Coupled fixed point theorems for nonlinear contractions in partially ordered metric spaces. Nonlinear Anal. 70, 4341-4349 (2009)

doi:10.1186/1687-1812-2012-215

Cite this article as: Amini-Harandi: Fixed and coupled fixed points of a new type set-valued contractive mappings in complete metric spaces. Fixed Point Theory and Applications 2012 2012:215.

\section{Submit your manuscript to a SpringerOpen ${ }^{\circledR}$ journal and benefit from:}

- Convenient online submission

- Rigorous peer review

Immediate publication on acceptance

- Open access: articles freely available online

- High visibility within the field

- Retaining the copyright to your article 